\title{
LIMITES DO EXERCÍCIO DO DIREITO DE RECUSA AO TRABALHO EM CONDIÇÕES DE RISCO GRAVE E IMINENTE.
}

\author{
Nilton B. B. Freitas \\ Coordenador Técnico Nacional do DIESAT \\ Assessor Técnico do Sind. Químicos do ABC \\ Mestrando em Saúde Pública pela ENPS/FIOCRUZ
}

O Direito de Recusa ao Trabalho em condições de risco grave foi introduzido nas Constituições dos Estados de São Paulo e Rio de Janeiro em 1989, sem que grandes manifestações de seu exercício tenham chegado ao conhecimento público. Longe de ser uma expressão de sua inutilidade, mais parece ser o reflexo de relações de trabalho comprometidas pela desigualdade e que, em última instância, dificulta o trabalhador usufruir seus direitos duramente conquistados.

Palavras-chaves: segurança do trabalho, riscos no trabalho

\section{Introdução}

Apenas a partir de 1.989 os trabalhadores brasileiros, ou melhor, parte deles passaram a gozar do direito de se recusar a adoecer e morrer nos locais de trabalho. Trata-se dos trabalhadores paulistas e cariocas que por ocasião da Assembléia Estadual Constituinte de seus Estados, promulgadas em 05 de outubro daquele ano, conseguiram a garantia de que não sofreriam represálias em caso de negativa a se expor a uma condição de risco grave e iminente (São Paulo) ou "sem controle adequado de riscos" (Rio de Janeiro).

A Carta paulista (SÃO PAULO, 1989) recebeu no seu artigo 229 do Capítulo II, a seguinte redação:

"Em condições de risco grave ou iminente no local de trabalho, será lícito ao empregado interromper suas atividades, sem prejuízo de quaisquer direitos, até a eliminação do risco."

A Carta carioca (RIO DE JANEIRO, 1989) por seu lado, é mais abrangente:

"Art. 290 - Ao Sistema Único de Saúde compete, além de outras atribuições estabelecidas na Lei Orgânica de Saúde: ...

$\mathrm{X}$ - Desenvolver ações visando à Segurança e à Saúde do Trabalhador, integrando Sindicatos e Associações Técnicas, compreendendo a fiscalização e coordenação geral na prevenção, prestação de serviços e recuperação mediante: ...

d) direito de recusa ao trabalho em ambientes sem controle adequado de riscos, assegurada a permanência no emprego;

e) ...; a h) ...; 
Tanto uma como a outra não foram entretanto regulamentadas na forma de lei, como ocorre comumente com direitos trabalhistas. Em São Paulo, as tentativas de sua regulamentação no bojo da organização do sistema de saúde e Código Sanitário, estão há anos aguardando pareceres conclusivos do Governo do Estado, fazendo com que o direito não seja usufruído ou fique restrito a conceituações ultrapassadas como aquela existente nas Normas Regulamentadoras da Consolidação das Leis do Trabalho - CLT.

\section{Limites da Conceituação}

RISCO GRAVE E IMINENTE, segundo a Norma Regulamentadora 3 (NR-3) da Portaria 3214 de 08 de junho de 1978 é "toda condição ambiental de trabalho que possa causar acidente do trabalho ou doença profissional com lesão grave à integridade física do trabalhador" (BRASIL, 1978).

As limitações desta definição legal são evidentes. Primeiro porque restringe o risco ao seu caráter ambientalista, que se expressa nos Agentes Físicos, Químicos, Biológicos e Mecânicos, excluindo os chamados riscos "da organização do trabalho", conhecidos como riscos sociais, ergonômicos ou organizacionais. (SATO et al., 1993; MATTOS, 1985; SIMONI \& MATTOS, 1982).

Em segundo lugar porque condiciona a natureza do risco à sua característica de relação causa-efeito direta com o trabalho (acidentes do trabalho ou doença profissional) excluindo o acidente de trajeto e a chamada doença do trabalho "cuja relação de causa e efeito com o trabalho não é tão direta como acontece com as doenças profissionais, e cujas causas são fatores relacionados com o ritmo de trabalho, com a postura, com o esforço físico, com o trabalho em turnos, com o controle que visa cada vez maior produtividade, com a alienação do trabalho ...". (DIESAT, 1989b, p. 65)

Por fim, porque exige que a lesão sofrida pelo trabalhador seja de "grave" intensidade à sua integridade física, excluindo desta vez a possibilidade de "lesão" de ordem mental ou emocional.

Esse caráter restritivo se choca com a realidade do trabalho no Brasil atual, bem como com a própria legislação e conhecimento preventista. Um exemplo clássico é a verdadeira epidemia de Lesões por Esforços Repetitivos (LER) que atinge indiscriminadamente homens e mulheres das mais diversas categorias profissionais e profissões: tecnologias ultrapassadas, ritmo elevado de produção, formas de organização do trabalho que eliminam pausas e intervalos para descanso são, isoladamente e principalmente juntos, potenciais causadores de LER, finalmente reconhecidas como doença profissional (MPS, 1993; SES/SP, 1992), que geralmente ocasionam lesões da mais alta gravidade.

Porém, ritmo de trabalho, tecnologia obsoleta e formas de gestão do trabalho não são considerados "condição ambiental de trabalho". O risco de LER ocasionar acidentes no trajeto casa-trabalho e vice-versa também é enorme devido à própria dificuldade de realização de esforços com mãos e braços, necessários para dirigir automóveis, subir em ônibus, locomover-se no metrô etc... 
Ademais, na realidade econômica brasileira, há que se ressaltar a extrema gravidade de QUALQUER doença para uma pessoa que vive da venda da sua força de trabalho num mercado caracterizado pela oferta de mão-de-obra maior que a demanda, diminuição estrutural do número de empregos, baixa qualificação da mão-de-obra, baixo nível de escolaridade, ausência endêmica de assistência social, de saúde, de moradia, de renda, etc ...

Ou seja, do ponto de vista do trabalhador qualquer condição que coloque em risco sua capacidade de produzir e de vender sua mão-de-obra ao capitalista é de extrema gravidade e importância, porque afinal está em risco sua possibilidade de sobrevivência e reprodução.

\section{Limites da Legislação}

A legislação de segurança e medicina do trabalho no Brasil está expressa na Portaria 3214 de 08/06/78 (BRASIL, 1978) que regulamentou a Lei 6514 de 22/12/77. A definição legal de risco grave e iminente acima comentada se materializa nas Normas Regulamentadoras (NRs),com os seguintes aspectos:

\section{i) Riscos Químicos}

a) Quando o Limite de Tolerância de uma substância listada no Anexo 11 da NR-15 é ultrapassada de 1,1 a 3 vezes, dependendo do produto;

b) Quando não forem hermeticamente vedados os processos envolvendo as seguintes substâncias cancerígenas: 4-Amido defenil (p-enilamina); Produção de Benzidina; Beta-naftilamina; 4-Nitrodifenil; (Anexo 13 da NR-15)

c) "Fica proibída a utilização de qualquer tipo de asbesto do grupo anfibólio e dos produtos que contenham essas fibras. Fica proibída a pulverização ('spray') de todas as formas de asbesto. Fica proibído o trabalho de menores de dezoito anos em setores onde possa haver exposição à poeira de asbesto." (Portaria n ${ }^{\circ} 01$ de 28/05/91) (MTPS, 1991)

\section{ii) Riscos Físicos}

a) Quando a temperatura ambiental for superior a $30^{\circ}$ graus IBUTG (índice de Bulbo úmido Termômetro de Globo), medida com termômetro de mercúrio e de bulbo úmido; (Anexo 3 da NR-15).

b) Quando o nível de ruído for superior a 115 decibéis e o trabalhador não dispuser de proteção adequada; (Anexo 1 da NR-15).

\section{iii) Riscos Mecânicos}

a) Serviços de manutenção, limpeza, ajustamento e inspeção somente podem ser feitos com o equipamento ou máquina parada, salvo se o funcionamento for essencial para a execução do próprio serviço; (NR-12)

b) Segundo a NR-12 é proíbido o uso de máquinas nas seguintes condições: 
1 - se os comandos de acionamento e parada da máquina ou equipamento estiverem longe do posto de trabalho do operador;

2 - se eles se localizarem em zona perigosa da máquina;

3 - se eles não puderem ser acionados em caso de emergência por terceiros;

4 - se eles correrem o risco de serem acionados acidentalmente;

5 - se a máquina ou equipamento não possuir chave geral de corte de eletricidade protegida e em local de fácil acesso;

6 - se a máquina ou equipamento que possuir mais de um botão de comando não dispuser de alarme sonoro quando um deles for acionado;

7 - quando as máquinas e equipamentos não tiverem suas correias, polias e outras partes móveis bem protegidas;

8 - quando as máquinas não possuírem anteparos contra o lançamento de partículas ou respingos;

9 - quando as máquinas e equipamentos não forem aterrados eletricamente;

c) Segundo a NR-13 constituem-se em condições de risco grave e iminente as Caldeiras e Vasos sob pressão:

1 - onde faltem manômetros e válvulas de segurança;

2 - com proximidade entre as caldeiras e os tanques de combustíves;

3 - onde faltem válvulas de segurança e outros dispositivos para evitar aumento de pressão interna;

4 - onde não se realizem inspeções periódicas anuais ou a cada 18 meses, com emissão de Relatório de Inspeção assinado por Engenheiro credenciado na DRT.

d) Nas obras de demolição, reforma ou construção são inúmeras as situações que podem se constituir em condição de risco grave e iminente, já previstas em lei:

1 - falta de proteção em serra circular;

2 - cabos de aço em mau estado de conservação;

3 - falta de escoramento em taludes e valas;

4 - falta de cinto de segurança em trabalho em altura;

5 - falta de isolamento de área sob cargas suspensas ou em áreas de tração de cabos;

6 - falta de amarração no transporte de feixes de vergalhão;

7 - falta de ventilação quando da aplicação de vernizes, colas, etc;

8 - falta de portas nos vãos de elevadores;

9 - transporte de pessoas em elevadores de carga;

10 - falta de proteção em partes energizadas;

11 - Outros.

Refletindo a restrita definição legal exposta no início deste trabalho, a normatização vigente também apresenta-se restrita aos chamados Riscos Ambientais e ainda assim de forma conservadora e até equivocada do ponto de vista da saúde. 
Substâncias reconhecidamente cancerígenas como Benzeno, Negro de Fumo, Asbesto e Cloreto de Vinila são toleradas com a ausência de restrições severas e até a proibição em alguns casos.

Aspectos da organização do trabalho, como pressão de chefia, perseguições, ritmo acelerado, trabalho monótono, acúmulo de tarefas e responsabilidade excessiva por exemplo, não são considerados como condição de risco grave e iminente embora sejam reconhecidamente causadoras de sofrimentos que podem se materializar em acidentes e doenças de ordem psicossomática, além de expressões diversas de desgaste mental. A gravidade de um evento desta natureza pode extrapolar o limite do indivíduo e alcançar a comunidade, caso ocorra em uma Central Petroquímica ou Nuclear, em transporte coletivo de massas ou transporte de cargas perigosas, por exemplo.

\subsection{Limites do SESMT e dos seus profissionais}

O artigo 162 do Capítulo V do Título II da CLT estabelece que as empresas, de acordo com o número de funcionários e o grau de risco de suas atividades para a saúde e segurança de seus empregados devem ter um SERVIÇO ESPECIALIZADO EM ENGENHARIA DE SEGURANÇA E MEDICINA DO TRABALHO - SESMT. A Norma Regulamentadora 4 (NR-4) da Portaria 3214 de 8/06/78 detalha melhor a constituição e funcionamento do Serviço.

Tabela 1- Quadro II: Dimensionamento do SESMT

\begin{tabular}{|c|c|c|c|c|c|c|c|c|c|}
\hline $\begin{array}{l}\text { grau de } \\
\text { risco }\end{array}$ & técnicos & $\begin{array}{l}50 \\
\mathrm{a} \\
10 \\
0\end{array}$ & $\begin{array}{l}10 \\
1 \\
\mathrm{a} \\
25 \\
0\end{array}$ & $\begin{array}{l}25 \\
1 \\
\mathrm{a} \\
50 \\
0\end{array}$ & $\begin{array}{c}501 \\
\mathrm{a} \\
1000\end{array}$ & $\begin{array}{l}1001 \\
\mathrm{a} \\
2000\end{array}$ & $\begin{array}{l}2001 \\
\mathrm{a} \\
3500\end{array}$ & $\begin{array}{l}3501 \\
\mathrm{a} \\
5000\end{array}$ & $\begin{array}{l}>5000 \mathrm{p} / \text { cada } \\
\text { grupo de } 4000 \\
\text { ou fração }>2000 \\
* *\end{array}$ \\
\hline 1 & $\begin{array}{l}\text { técnico seg. trabalho } \\
\text { engenheiro seg. trabalho } \\
\text { aux.enfermagem } \\
\text { do trabalho } \\
\text { enfermeiro do trabalho } \\
\text { medico do trabalho } \\
\end{array}$ & & & & 1 & $1^{*}$ & $\begin{array}{l}1 \\
1^{*} \\
1\end{array}$ & $\begin{array}{l}2 \\
1 \\
1 \\
\\
1^{*} \\
1\end{array}$ & $\begin{array}{l}1 \\
1^{*} \\
1\end{array}$ \\
\hline 2 & $\begin{array}{l}\text { tecnico seg. trabalho } \\
\text { engenheiro seg. trabalho } \\
\text { aux.enfermagem } \\
\text { do trabalho } \\
\text { enfermeiro do trabalho } \\
\text { medico do trabalho } \\
\end{array}$ & & & & 1 & $\begin{array}{l}1 \\
1^{*} \\
1\end{array}$ & $\begin{array}{l}2 \\
1 \\
1\end{array}$ & $\begin{array}{l}5 \\
1 \\
1 \\
1 \\
1 \\
1\end{array}$ & $\begin{array}{l}1 \\
1 * \\
1\end{array}$ \\
\hline 3 & $\begin{array}{l}\text { tecnico seg. trabalho } \\
\text { engenheiro seg. trabalho } \\
\text { aux.enfermagem } \\
\text { do trabalho }\end{array}$ & & 1 & 2 & $\begin{array}{l}3 \\
1^{*}\end{array}$ & $\begin{array}{l}4 \\
1 \\
1\end{array}$ & $\begin{array}{l}6 \\
1 \\
2\end{array}$ & $\begin{array}{l}8 \\
2 \\
1\end{array}$ & $\begin{array}{l}3 \\
1 \\
1\end{array}$ \\
\hline
\end{tabular}




\begin{tabular}{|c|c|c|c|c|c|c|c|c|c|}
\hline & $\begin{array}{l}\text { enfermeiro do trabalho } \\
\text { medico do trabalho }\end{array}$ & & & & $1 *$ & 1 & 1 & $\begin{array}{l}1 \\
2\end{array}$ & 1 \\
\hline & tecnico seg. trabalho & 1 & 2 & 3 & 4 & 5 & 8 & 10 & 3 \\
\hline & engenheiro seg. trabalho & & $1 *$ & $1^{*}$ & 1 & 1 & 2 & 3 & 1 \\
\hline 4 & aux.enfermagem & & & & 1 & 1 & 2 & 1 & 1 \\
\hline & $\begin{array}{l}\text { enfermeiro do trabalho } \\
\text { medico do trabalho }\end{array}$ & & $1 *$ & $1 *$ & 1 & 1 & 2 & $\begin{array}{l}1 \\
3\end{array}$ & 1 \\
\hline
\end{tabular}

(*) - Tempo parcial (mínimo de três horas)

$(* *)$ - O dimensionamento total deverá ser feito levando-se em consideração o dimensionamento da faixa de 3501 a 5000 mais o dimensionamento do(s) grupo(s) de 4000 ou fração acima de 2000.
OBS: Hospitais, Ambulatórios, maternidades, Casas de Saúde e Repouso, Cínicas e estabelecimentos similares com mais de 500 (quinhentos) empregados deverão contratar um Enfermeiro do trabalho em tempo integral.

No seu item 4.1 a NR-4 estabelece que: "As empresas privadas e públicas, os orgãos públicos da administração direta e indireta e dos poderes Legislativo e Judiciário, que possuam empregados regidos pela Consolidação das Leis do Trabalho CLT manterão, obrigatoriamente, Serviços Especializados em Engenharia de Segurança e em Medicina do Trabalho, com a finalidade de promover a saúde e proteger a integridade do trabalhador no local de trabalho."

Os técnicos previstos para compor o SESMT são os seguintes: Técnico de Segurança do Trabalho; Engenheiro de Segurança do Trabalho; Auxiliar de Enfermagem do Trabalho; Enfermeiro do Trabalho e Médico do Trabalho.

Como se pode observar na tabela 1 e como já tem sido fartamente demonstrado (MENDES, 1990; BARREIROS, 1990; MELO, 1990), a maior parte dos estabelecimentos no país são desobrigados de organizar e manter SESMT, apesar de serem os locais de maior ocorrência e gravidade dos acidentes.

Isto porque o SESMT só passa a ser exigido nas empresas com mais de 50 empregados, assim mesmo naquelas de Grau de Risco 4 (universo restrito das usinas nucleares, atividades de mergulho e estiva, extração mineral e vegetal e siderurgia em geral). As empresas de Grau de Risco 3, com universo pouco maior só passam a serem obrigadas a ter SESMT quando empregarem mais de 101 trabalhadores. Apenas as empresas com mais de 501 empregados são obrigadas a ter SESMT a partir do Grau de Risco 1 (geralmente atividades administrativas como escritórios, bancos, associações, fundações, etc).

"De acordo com o Censo do IBGE de 1.980 , cerca de 74,4\% da população trabalhadora industrial estava empregada em empresas com até 499 empregados". (MENDES, 1986)

O Cadastro de Empresas de Maio de 1.991 do Sindicato dos Químicos do ABC (ASCIUTTI, 1993) demonstrava que de um universo de 472 empresas apenas 17 (3,5\% do total) situava-se na faixa com número de empregados acima de 501 trabalhadores, obrigadas desta forma a terem 1 Médico do Trabalho no seu SESMT, na medida que são consideradas na sua maioria Grau de Risco 3. Estas empresas empregavam naquele ano, segundo a mesma fonte, cerca de 16.000 trabalhadores (ou $37,4 \%$ da categoria). O restante dos trabalhadores químicos (cerca de 27.000 cadastrados) eram, por lei, desassistidos da atenção de Médico do Trabalho, embora as condições de trabalho nas pequenas e médias empresas sejam sabidamente piores que 
nas grandes, com maior capacidade de investimento e onde os trabalhadores são mais organizados e mais exigentes. (BARREIROS, 1990)

Para MENDES (1986), os estabelecimentos industriais que possuem SESMT não ultrapassam cerca de $2 \%$ do total, correspondendo à cerca de $35 \%$ da força de trabalho empregada.

Além da sua abrangência restrita, a limitação de suas atribuições impede o SESMT de ter uma atuação decisiva contra os acidentes e doenças nas empresas onde está organizado, particularmente contra as condições de risco grave e iminente. Entre essas atribuições destacam-se apenas as seguintes neste sentido:

"a) aplicar os conhecimentos de Engenharia de Segurança e de Medicina do Trabalho ao ambiente de trabalho e a todos os seus componentes, inclusive máquinas e equipamentos, de modo a reduzir até eliminar os riscos ali existentes à saúde do trabalhador;

$\begin{array}{ll}\text { b) } \ldots & \text { c) } \ldots\end{array}$

d) responsabilizar-se tecnicamente, pela orientação quanto ao cumprimento do disposto nas NR's aplicáveis às atividades executadas pela empresa e/ou seus estabelecimentos;

e) ... a l) ...;"

Ou seja, aos profissionais do SESMT é dado apenas o dever de orientar empregados e empregador sobre as condições de risco (inclusive quando grave e iminente), sem terem no entanto qualquer poder de paralização ou interdição da atividade.

A Resolução 325 de 27/11/87 do Conselho Federal de Engenharia, Arquitetura e Agronomia - CONFEA, define em seu art. $4^{\circ}$ "As atividades de Segurança do Trabalho", nada relatando em especial quanto às condições de risco grave e iminente. No entanto, o ítem 18 destas atribuições determina que o Engenheiro deve "Informar aos trabalhadores e à comunidade, diretamente ou por meio de seus representantes, as condições que possam trazer danos à sua integridade e as medidas que eliminam ou atenuam estes riscos e que deverão ser tomadas."

O Código de Ética Médica contém artigos que definem a postura do profissional empregado em empresas frente aos riscos à saúde nos locais de trabalho:

"Artigo 11 - O médico deve manter sigilo quanto às informações confidenciais de que tiver conhecimento no desempenho de suas funções. O mesmo se aplica ao trabalho em empresas, exceto nos casos em que seu silêncio prejudique ou ponha em risco a saúde do trabalhador ou da comunidade;

Artigo 12 - O médico deve buscar a melhor adequação do trabalho ao ser humano e a eliminação ou controle dos riscos inerentes ao trabalho;

É vedado ao médico:

Artigo 4 - Deixar de esclarecer o trabalhador sobre as condições de trabalho que ponham em risco sua saúde, devendo comunicar o fato aos responsáveis, às autoridades e ao Conselho Regional de Medicina;"

\subsection{Limite da Cipa e dos Cipistas}


O "Livro da CIPA" de autoria do médico Márcio dos Santos MELO (1990), destaca à página 48: "A legislação brasileira é omissa sobre o papel da CIPA nessas situações (de risco grave e iminente). Em outros países, membros de comissões semelhantes à CIPA em situação de risco grave e iminente podem interditar máquinas, locais de trabalho, etc. $\mathrm{O}$ fato de a legislação não oferecer orientação não significa, todavia, que a CIPA e seus membros devam assumir uma postura omissa diante de tais fatos. Dependendo das condições particulares de cada empresa, das relações dos cipeiros e da CIPA com o empregador e com os representantes sindicais, devem ser tomadas atitudes visando o bloqueio imediato dessas situações de trabalho."

Em 11 de março de 1990 a então Ministra do Trabalho Dorothéa Werneck assinou Portaria (MINISTÉRIO DO TRABALHO, 1990) modificando a NR-5 que trata do funcionamento da CIPA. Entre as inúmeras inovações constava, no ítem 5.7.2.2 a possibilidade da CIPA interditar máquinas e equipamentos ou condições ambientais que apresentassem condição de risco grave e iminente à saúde e à segurança dos trabalhadores. Tal Portaria não chegou a ser publicada no Diário Oficial da União por intervenção do então Ministro da Justiça do Governo Sarney, Sr. Saulo Ramos, atento e sensível às posições empresariais.

\subsection{Limites do Ministério do Trabalho}

O artigo 161 do Capítulo V do Título II da CLT estabelece em seu parágrafo $2^{\circ}$ que as entidades sindicais poderão requerer ao Delegado Regional do Trabalho (autoridade máxima do Ministério do Trabalho nos Estados) a interdição ou embargo de obra, estabelecimento, setor de serviço, máquina ou equipamento que "demonstre grave e iminente risco para o trabalhador."

A autoridade, à vista de laudo técnico do serviço competente, poderá determinar o embargo ou interdição com a urgência exigida, estaduais ou municipais.

No entanto, em seu cotidiano os sindicatos enfrentam inúmeras dificuldades para executar aquilo que a lei lhes garante. Estas dificuldades podem ser resumidas na própria inoperância crônica do Ministério do Trabalho, expressa basicamente por:

1 - Falta de agentes fiscais especializados em segurança e medicina do trabalho na maioria dos Estados e Sub-Delegacias;

2 - Falta de equipamentos básicos de medição ambiental para ruído, calor, agentes químicos, etc;

3 - Falta de recursos materiais para deslocamento de fiscais, andamento de processos, etc;

4 - Falta de recursos humanos administrativos que impedem inclusive a execução de multas, elaboração de laudos, etc;

Alguns Delegados confiam aos agentes fiscais especializados de suas unidades a autonomia necessária para a interdição ou embargo imediato de situações de risco 
grave e iminente, tornando secundário a elaboração de laudo técnico e o despacho da autoridade. Tal medida agiliza as ações e aumenta a eficiência da fiscalização. No entanto, ela não é generalizada.

\section{O Papel dos Sindicatos}

Frente às limitações impostas pela lei às CIPAs, SESMT e até mesmo DRTs e Normas específicas, o movimento sindical passou a buscar a partir da década de 80 alterações no "status quo" legal que permitissem a defesa da saúde e da vida dos trabalhadores.

Assim sendo, além das pressões sistemáticas da luta cotidiana sobre os donos das empresas e os governantes de plantão no MTb, o movimento sindical mais combativo nas questões de saúde, particularmente aquele organizado junto ao DIESAT - Departamento Intersindical de Estudos e Pesquisas de Saúde e dos Ambientes de Trabalho - nos anos 88/89, implementou uma série de medidas que culminou com a aprovação do "Direito de Recusa" nas Constituintes dos Estados de São Paulo e Rio de Janeiro naquele último ano.

Além disso, imediatamente algumas categorias (como os Químicos da CUT do Estado de São Paulo) conseguiram regulamentar o artigo constitucional nos seus Acordos e Convenções Coletivas (FEDERAÇÃO DOS QUÍMICOS DO OESP, 1992; DIESAT, 1989a), com a seguinte redação:

"Quando o trabalhador, no exercício de sua função, entender que sua vida ou integridade física se encontram em risco, pela falta de medidas adequadas de proteção no posto de trabalho, poderá suspender a realização da respectiva operação (o próprio trabalho), comunicando imediatamente tal fato ao seu superior e ao setor de segurança, higiene e medicina do trabalho da empresa, cabendo a este investigar eventuais condições inseguras e comunicar o fato à CIPA. O retorno à operação se dará após a liberação do posto de trabalho pelo referido setor."

Ou ainda a Cláusula de Acordo entre Sindicato dos Bancários de São Paulo e BANESPA:

"É permitido ao empregado o direito de não executar qualquer atividade que cause dano à sua saúde ou integridade física, desde que não lhe sejam asseguradas as mínimas condições de segurança" (DIESAT, 1989a).

No entanto, os registros de usufruto desta conquista constitucional e trabalhista têm sido restritos. Embora haja indícios de usufruto individual e muitas vezes não explícito e assumido devido ao medo de represálias, apenas o movimento dos Servidores Municipais da Fábrica de Caixões da Prefeitura de São Paulo em 1990 e, o dos trabalhadores da Petroquímica União, de Santo André em 1992, são conhecidos. O primeiro foi ocasionado pelas péssimas condições de trabalho em geral, com destaque para o contacto com metanol dos veículos e ruído excessivo. O segundo ocorreu após uma série de 3 explosões que vitimou fatalmente um trabalhador e feriu outros 10, levando ao questionamento das condições de manutenção dos equipamentos, 
treinamento e qualificação da mão-de-obra, procedimentos operacionais e outras questões organizacionais.

Nas duas ocasiões os trabalhadores, com apoio e incentivo dos seus Sindicatos (SINDSEP/SP e Sindiquim ABC), proclamaram seu direito de não continuar trabalhando em condições nocivas à sua segurança e saúde, paralisando o trabalho e negociando com os empregadores as melhorias e correções necessárias. (FREITAS, 1989; SINDICATO DOS QUÍMICOS DO ABC - CUT - ICEF, 1992)

As estatísticas mais recentes parecem explicitar tacitamente a intocabilidade da realidade dos acidentes e mortes no trabalho. Segundo dados do INSS organizados pelo Centro de Vigilância Epidemiológica da Secretaria de Estado da Saúde de São Paulo- CVE/SES/SP, a gravidade dos acidentes do trabalho no Estado e Município de São Paulo, mantiveram sua curva ascendente mesmo após a promulgação da Constituição do Estado, refletindo talvez a ausência de sua regulamentação, a distância do "status quo" da Carta ao cotidiano do cidadão comum ou ainda sua restrição enquanto direito individual que ainda não atingiu, salvo exceções, o caráter de coletivo.

\section{Conclusões}

As limitações conceituais de "risco grave e iminente" da legislação brasileira se espalham nas Normas técnicas vigentes, limitando sua abrangência e dos órgãos responsáveis pela fiscalização e prevenção. Daí a importância da inclusão do "direito de recusa" nas constituições dos Estados industrialmente mais desenvolvidos do país e nos Acordos Coletivos das principais categorias econômicas.

No entanto, sua utilização ainda pequena pelos trabalhadores e a violência crescente no trabalho a julgar pelo número de mortes cada vez maior, demonstra que a problemática do acidente do trabalho no Brasil é muito mais complexa do que a simples questão tecnológica e legal propriamente dita.

Enquanto não forem superados os tabus e preconceitos que impedem que o Brasil adote modelos de relação no trabalho embasados na democracia e cidadania, possibilitando a mais ampla organização e participação dos trabalhadores nas questões relacionadas à organização do trabalho, mesmo os direitos elementares arduamente conquistados não poderão ser usufruídos, devido ao império do autoritarismo no poder de mando do empregador dentro da fábrica.

DWYER (1992), relata que "quando os trabalhadores são levados por medo de punição, a executar tarefas que julgam perigosas, os acidentes decorrentes são atribuídos à relação social do AUTORITARISMO. A principal força para combater o autoritarismo é um movimento sindical forte. Turner relatou um aumento de $40 \%$ na taxa de acidentes numa fábrica de automóveis após a demissão de um grupo de pessoas rotuladas pela gerência "agitadoras".

Faz-se portanto urgente a regulamentação do Direito de Recusa na legislação de proteção à saúde dos Estados de São Paulo e Rio de Janeiro, além de sua extensão para todo o país, por meio de normas federais que sejam acompanhadas de transformação no caráter da forma de contratação do trabalho no Brasil, ultrapassando 
os limites do modelo individualista da CLT, rumo ao Contrato Coletivo de Trabalho e à livre organização dos trabalhadores, dentro e fora da fábrica.

\section{Referências Bibliográficas:}

ASCIUTTI, C.M.: Pesquisa - Os Portadores de um Ofício - O saber do trabalhador. IADES/Sindicato dos Químicos e Petroquímicos e Similares do ABCDM-SP. Fevereiro/1993.

BARREIROS, D.: "Saúde e Segurança nas pequenas empresas". Revista Brasileira de Saúde Ocupacional. (FUNDACENTRO), São Paulo, Vol. 18, n. 70, p. 25-28, Abril/Maio/Junho/1990.

BRASIL: Ministério do Trabalho. Portaria no 3214 de 08/06/78: Segurança e Medicina do Trabalho - $\mathbf{1 5}^{\mathbf{a}}$ ed (Manuais de Legislação Atlas, 16). Editora Atlas, São Paulo, 1989.

DIESAT: "Cláusulas de Saúde nas Convenções Coletivas de quatro sindicatos". Revista Trabalho \& Saúde, Ano VIII, n² 26, p. 7-10, Nov/Dez/1989a.

DIESAT: Insalubridade, Morte Lenta no Trabalho. Oboré, São Paulo, 1989b.

DWYER, T.: "Acidentes, questão política". Jornal da Tarde, Sábado, 02/05/1992.

FEDERAÇÃO DOS QUÍMICOS DO ESTADO DE SÃO PAULO - CUT: Acordo Coletivo 92/93. Federação dos Químicos do Estado de São Paulo, São Paulo, 1992.

FREITAS, N.B.B.: Relatório de Vistoria - Serviço Funerário do Município de São Paulo. Laudo Técnico DIESAT, Sindicato dos Servidores Públicos Municipais de São Paulo. São Paulo, 28/05/1989. (27 p.)

MATTOS, U.A.O.: "Metodologia para Estudos e Projetos em Higiene e Segurança do Trabalho - MEPHISTO. Revista Brasileira de Saúde Ocupacional (FUNDACENTRO), São Paulo, Vol. 13, número 51. Jul/Ago/Set 1985.

MELO, M.S.M.: Livro da CIPA - Manual de Segurança e Saúde no Trabalho. FUNDACENTRO, São Paulo, 1990. (236 p.)

MENDES, R.: Doutrina e prática da integração da saúde ocupacional no setor saúde: contribuição para a definição de uma política. Tese Livre Docência Faculdade Saúde Pública - USP, São Paulo, 1986. (384 p)

MENDES, R.: "Importância das Pequenas Empresas Industriais no Problema de Acidentes do Trabalho em São Paulo". Revista Brasileira de Saúde Ocupacional. (FUNDACENTRO), São Paulo, Vol. 18, n. 70, p. 53-58, Abril/Maio/Junho/1990.

MINISTÉRIO DO TRABALHO: Portaria 3047 de 08/03/90 - NR-5 Comissão Interna de Prevenção de Acidentes - CIPA, MTb, Brasília, 1990. 
MPS - MINISTÉRIO DA PREVIDÊNCIA SOCIAL: LER - Lesões por Esforços Repetitivos. Normas Técnicas para Avaliação da Incapacidade - 1993. INSS. Brasília, 1993.

RIO DE JANEIRO: Constituição do Estado. Promulgada em 05 de Outubro de 1.989.

SÃO PAULO: Constituição do Estado. Imprensa Oficial do Estado S.A. - IMESP, São Paulo, 1989

SATO, L. et al.: "Mapa de Risco: da sua origem à sua aplicação legal" (mimeo). DIESAT, São Paulo, Maio/1993.

SES/SP: Resolução SS-197, de 08/06/92, D.O.E., São Paulo, 16/06/1992.

SIMONI, M. \& MATTOS, U.A.O.: "Roteiro de Projeto em Higiene e Segurança do Trabalho". DEP/UFSCar, São Carlos, 1982

SINDICATO DOS QUÍMICOS DO ABC - CUT - ICEF: Parar a produção para não parar a vida. Sind. Químicos e Petroquímicos do ABC, Novembro de 1992.

MTPS - SNT - DST: Portaria $\mathbf{n}^{0} 01$ de 28 de maio de 1991. D.O.U., Brasília, 29/05/1991.

\title{
BOUNDARIES OF THE RIGHT TO REFUSE TO WORK UNDER SERIOUS DANGEROUS CONDITIONS
}

\begin{abstract}
The right to refuse to work under serious dangerous conditions was introduced in the Constitutions of Sao Paulo and Rio de Janeiro States in 1989. The impact of these measures did not reach public knowledge. It was not an expression of its uselessness. It seems to be the result of an unequal work relationship that, in the last instance, difficultates the worker usufruct of his rights gained in a hard process.
\end{abstract}

Key-words: work assurance, work risks. 